\title{
Review
}

\section{New targets for therapy in breast cancer Mammalian target of rapamycin (mTOR) antagonists} Hetty Carraway and Manuel Hidalgo

\author{
Sidney Kimmel Comprehensive Cancer Center at Johns Hopkins Hospital, Cancer Research Building, Baltimore, Maryland, USA \\ Corresponding author: Hetty Carraway, hcarraw1@jhmi.edu
}

Published: 12 August 2004

Breast Cancer Res 2004, 6:219-224 (DOI 10.1186/bcr927)

(c) 2004 BioMed Central Ltd (Print ISSN 1465-5411; Online ISSN 1465-542X)

\begin{abstract}
Mammalian target of rapamycin (mTOR) is a serine-threonine kinase member of the cellular phosphatidylinositol 3-kinase (PI3K) pathway, which is involved in multiple biologic functions such as transcriptional and translational control. mTOR is a downstream mediator in the PI3K/Akt signaling pathway and plays a critical role in cell survival. In breast cancer this pathway can be activated by membrane receptors, including the HER (or ErbB) family of growth factor receptors, the insulin-like growth factor receptor, and the estrogen receptor. There is evidence suggesting that Akt promotes breast cancer cell survival and resistance to chemotherapy, trastuzumab, and tamoxifen. Rapamycin is a specific mTOR antagonist that targets this pathway and blocks the downstream signaling elements, resulting in cell cycle arrest in the $\mathrm{G}_{1}$ phase. Targeting the Akt/PI3K pathway with mTOR antagonists may increase the therapeutic efficacy of breast cancer therapy.
\end{abstract}

Keywords CCl-779, epidermal growth factor receptor, mammalian target of rapamycin, phosphatidylinositol 3kinase pathway, PTEN

\section{Introduction}

Mammalian target of rapamycin (mTOR) is a serinethreonine kinase member of the cellular phosphatidylinositol 3-kinase (PI3K) pathway, which is involved in multiple functions such as transcriptional and translational control. Activation of mTOR as a consequence of nutrients and growth factors results in the phosphorylation and activation of the $40 \mathrm{~S}$ ribosomal protein S6 kinase $\left(p 70^{S 6 K}\right)$ and the eukaryotic initiation factor 4E-binding protein-1 (4EBP1; Fig. 1). These proteins play a key role in ribosomal biogenesis and cap-dependent translation, which result in increased translation of mRNAs that are important to the control and progression of the cell cycle. mTOR is a downstream mediator in the PI3K/Akt signaling pathway and plays a critical role in cell survival.

It has been shown that Akt regulates mTOR through the tuberous sclerosis (TSC) complex [1]. Under nonstimulated conditions, the TSC complex acts as a negative regulator of mTOR. Phosphorylation of TSC2 (tuberin) by Akt inactivates the complex, releasing its inhibitory effects on mTOR and resulting in mTOR activation. In addition, TSC regulation of mTOR is mediated by the small $G$ protein Rheb. When in its GTP state, Rheb is a potent activator of mTOR. Phosphorylated TSC shifts Rheb to the inactive GDP state [2].

In breast cancer the PI3K/Akt pathway can be activated by membrane receptors, including the HER (or ErbB) family of growth factor receptors, the insulin-like growth factor (IGF) receptor, and the estrogen receptor (ER) [3]. Stimulation of the PI3K/Akt pathway can also occur through oncogenic Ras. There is evidence suggesting that Akt promotes breast cancer cell survival and resistance to chemotherapy, trastuzumab, and tamoxifen [4-7]. This suggests that targeting the Akt/PI3K pathway with mTOR antagonists may increase the therapeutic efficacy of breast cancer therapy. Rapamycin and rapamycin analogs 
Figure 1

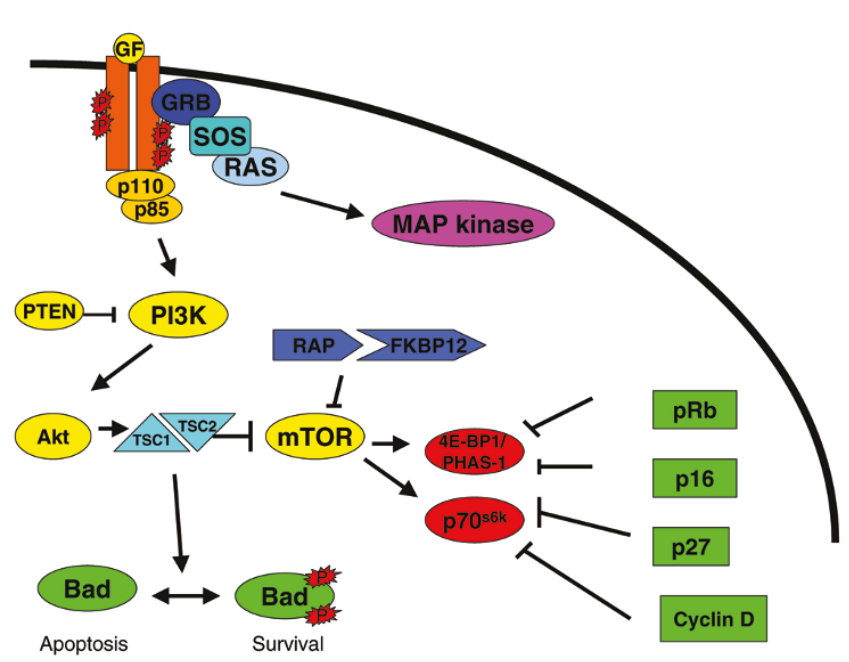

Rapamycin-sensitive signal transduction pathways. Both rapamycin and rapamycin analogs bind to the immunophilin FK506 binding protein-12 (FKBP-12). The rapamycin-FKBP12 complex binds to mammalian target of rapamycin (mTOR), inhibiting its kinase activity, which in turn inhibits the phosphorylation and activation of the downstream translational regulators 4EBP1/PHAS-1 and p70S6K. These downstream effects decrease the translational processing of mRNA for specific proteins that are essential for $G_{1}$ to $S$ phase transition. 4E-BP1, 4E binding protein-1; GF, growth factor; GPB, growth factor receptor bound; MAP, mitogen activated protein kinase; PI3K, phosphatidylinositol 3-kinase; PHAS, phosphorylated heat and acid stable protein; $p R b$, retinoblastoma protein; PTEN, phosphatase and tensin homologue deleted from chromosome 10; RAP, rapamycin; SOS, son-of-sevenless; TSC, tuberous sclerosis complex.

(CCl-779, RAD001, AP23573) are specific mTOR antagonists that are used to target this pathway and block the downstream signaling elements and result in cell cycle arrest in the $G_{1}$ phase. These agents have exhibited impressive growth inhibitory effects against a broad range of human cancers, including breast cancer, in preclinical and early clinical evaluations $[8,9]$.

Rapamycin is a macrolytic lactone produced by Streptomyces hygroscopicus, which has immunosuppressive, antimicrobial, and antitumor properties. Rapamycin binds intracellularly to FK506 binding protein12 (tacrolimus-binding protein) and targets a principal protein kinase that was named mTOR. Other names include FKBP-rapamycin associated protein (FRAP), rapamycin FKBP12 target (RAFT1), and rapamycin target (RAPT1). Inhibition of the phosphorylation of mTOR by rapamycin specifically blocks the activation of the $40 \mathrm{~S}$ ribosomal protein $\mathrm{S} 6$ kinase and 4E-binding protein-1, and directly reduces the translation of mRNAs that encode essential components of the protein synthesis machinery, including growth factors, oncoproteins, and cell cycle of cyclin-dependent kinase activation, inhibition of phosphorylation of the retinoblastoma protein, and acceleration of the turnover of cyclin $D_{1}$ mRNA and protein, leading to a deficiency of active cyclin-dependent kinase 4/cyclin D1 complexes. The combination of these events likely contributes to the prominent inhibitory effects of rapamycin at the $G_{1} / S$ boundary of the cell cycle, induction of apoptosis, and inhibition of angiogenesis in several preclinical cancer models [10].

Rapamycin was found to be a potent fungicide, particularly against Candida albicans and other filamentous fungi. Later, another related derivative was identified and found to be a potent immunosuppressant (tacrolimus). In bone marrow transplant research, further evaluation of the immunosuppressive qualities of rapamycin revealed successful activity in reversing acute allograft rejection and enhancing long-term donor-specific allograft tolerance. Because this drug is a potent immunosuppressant with negligible toxicity, it has regulatory approval for use in the prevention of allograft rejection after organ transplantation.

Rapamycin was found to have antiproliferative actions in a diverse range of experimental tumors, including lymphoma, small cell lung cancer, and rhabdomyosarcoma [11-13]. Antitumor actions of rapamycin have been principally attributed to its ability to modulate the synthesis of critical proteins that are required for ribosome biosynthesis, protein translation, and $G_{1}$ to $S$ cell cycle phase progression. Rapamycin's poor aqueous solubility and chemical stability limited its development as an anticancer agent, and consequently rapamycin analogs with more favorable pharmaceutical characteristics were developed, including CCl-779, RAD 001, and AP23573.

Although not all of the relevant elements of rapamycinsensitive signal transduction pathways have been elucidated, PI3K/Akt appears to be the key modulating element in the upstream pathway by which interactions between growth factors and growth factor receptors affect the phosphorylation state of mTOR. The enzyme PI3K, which plays a central role in cellular proliferation, motility, neovascularization, viability and senescence, is upregulated in many types of malignant cells. The best characterized effector of PI3K is the serine/threonine kinase Akt. Both $\mathrm{PI} 3 \mathrm{~K}$ and Akt are proto-oncogenes, because they have been demonstrated to possess cell-transforming properties. PI3K has other downstream effectors, but the Akt pathway is of particular interest because of its role in inhibiting apoptosis and promoting cell proliferation.

With regard to breast cancer pathogenesis, elements of the PI3K/Akt pathway have been demonstrated to be activated by the ErbB family, IGF receptor, and oncogenic Ras [14-17]. Over-expression of IGF-I receptor and IGF-I 
commonly occurs in breast cancers, and circulating IGF-I has been related to the risk for developing breast cancer [18-21]. Furthermore, elements of the IGF signaling pathway are found to be highly expressed in primary breast tumors, and overexpression of IGF pathway elements has been associated with poor prognosis [22]. Upon ligand binding, IGF-I receptor activates insulin receptor substrates that activate elements that are involved in signaling through the PI3K/Akt pathway. Breast tumors can possess genetic alterations in the PI3K/Akt pathway and often exhibit high levels of constitutive Akt activity. Recently, a high frequency of mutations of the PIK3CA gene was reported in $32 \%$ of colon cancers and almost $10 \%$ of breast cancers [23]. This may be a useful tool to identify which patients may respond to rapamycindirected therapy.

ER activation can directly drive the PI3K/Akt pathway [24]. Cross-talk between ErB1 and ER has been shown to activate the PI3K/Akt pathway, which has been associated with estrogen-independent transcriptional activity and antiestrogen resistance [2-5]. In support of this hypothesis, breast cancer cell lines with constitutively active Akt can proliferate in the absence of exogenous estrogen and are resistant to the growth inhibitory and proapoptotic effects of tamoxifen in vitro and in vivo [25]. The role played by the PI3K/Akt pathway in the development of estrogen resistance is also supported by studies of IGF. For example, IGF-I has been demonstrated to downregulate the progesterone receptor via a transcriptional mechanism that involves the PI3K/Akt pathway and is independent of the ER. These data may provide an explanation for why progesterone receptor negative tumors are particularly insensitive to estrogen deprivation [26].

Additional evidence points to a rationale for targeting the PI3K/Akt pathway in the treatment of breast cancer. Overexpression of D-type cyclin has been reported in approximately $50 \%$ of invasive breast cancers and was found to be associated with tumor progression $[27,28]$.

Upstream regulators of the PI3K/Akt pathway include the tumor suppressor gene PTEN (phosphatase and tensin homolog deleted from chromosome 10). PTEN inhibits the activity of PI3K. Thus, loss of PTEN suppressor gene function has been associated with Akt activation. A familial syndrome characterized by germline mutations in PTEN appear to be responsible for Cowden's syndrome, which predisposes to the development of several types of malignant neoplasms, including breast cancer. Another familial syndrome is Bannayan-Zonana, which has similar features. It is important to note that fewer than $5 \%$ of breast tumors harbor a PTEN mutation. However, hemizygous deletions of the PTEN locus and subsequent lack of PTEN protein occurs in about $30-40 \%$ of patients with sporadic breast cancer. This heterozygosity of the PTEN locus is associated with an increased activation of Akt [29-33]. The hyperactivation of PI3K/Akt signaling elements in PTEN-deficient malignancies suggests that these cancers are dependent on this pathway for growth and maintenance. Furthermore, experiments conducted in PTEN knockout mice indicate that PTEN-deficient cancers are extraordinarily sensitive to the growth inhibitory effects of rapamycin and rapamycin analogs [34]. Interestingly, treatment of doxorubicin-resistant and PTEN-defective prostate cancer cells with $\mathrm{CCl}-779$ has been shown to reverse doxorubicin resistance [35]. Transfection of those prostate cancer cells with functional PTEN produced a similar modulatory effect, suggesting that doxorubicin resistance in this model is mediated through the downstream activation of mTOR.

In breast cancer cells, PI3K/Akt and mTOR pathways appear to be critical for the proliferative responses mediated by epidermal growth factor receptor, the IGF receptor and the ER. These findings suggest that it may be rational to pursue the use of pharmacologic inhibitors of mTOR in treating patients with breast cancers, particularly because these malignancies have evidence of hyperactive PI3K/Akt signaling elements and/or aberrations in tumor suppressor proteins such as PTEN.

\section{Clinical studies with rapamycin/rapamycin analogs}

The safety and efficacy of rapamycin in the prevention of organ rejection have been demonstrated in two randomized, double-blind, multicenter, controlled trials involving over 1000 adult patients according to the investigator brochure for $\mathrm{CCl}-779$ formulation. Typical dosing was $2 \mathrm{mg}$ or $5 \mathrm{mg}$ administered daily. In these and most other trials, rapamycin has been administered with cyclosporine and corticosteroids, and limited pharmacokinetic PK data are available alone in this setting. Major side effects noted in these studies included thrombocytopenia, hypercholesterolemia, hypertriglyceridemia, and diarrhea. Renal function was not impaired.

The water-soluble rapamycin ester $\mathrm{CCl}-779$ was selected for clinical development through collaborative efforts between Wyeth-Ayerst Laboratories and the National Cancer Institute. In the US National Cancer Institute's 60 tumor type-specific cell line screening panel, $\mathrm{CCl}-779$ and rapamycin had nearly identical growth inhibitory profiles and $50 \%$ inhibitory concentration $\left(\mathrm{IC}_{50}\right)$ values that were frequently in the nanomolar range according to the investigator brochure for $\mathrm{CCl}-779$ formulation. Cell lines derived from breast, prostate, and small cell lung cancer were among the most sensitive to $\mathrm{CCl}$-779. In further laboratory-based studies by Wyeth, breast cancer cell lines (BT-474, SK BR-3, and MCF-7) exhibited extraordinary sensitivity to $\mathrm{CCl}-779$, with $\mathrm{IC}_{50}$ values ranging from 0.0006 to $0.001 \mu \mathrm{mol} / /$ [34]. Most breast cancer cell lines 
highly sensitive to $\mathrm{CCl}-779$ were found to be estrogen dependent, over-expressed Erb-2, and/or had PTEN deletions [21]. The resistant breast cancer cell lines lacked these features. Furthermore, sensitive breast cancer cell lines generally had higher levels of activated Akt, perhaps leading to downstream activation of MTOR and subsequent sensitivity to mTOR inhibitors. Laboratory data have also supported the synergistic growth inhibitory effects of MCF-7 breast cancer cell lines and xenografts with combinations of $\mathrm{CCl}-779$ and $\mathrm{ER}$ antagonists. Recently, both control MCF-7 and MCF-7/Aro (aromatase expressing) cells were found to be sensitive to treatment with the rapamycin analog RAD001 in vitro. RAD001 was found to almost completely inhibit estradiol induced proliferation in both control MCF-7 cells as well as estradiol and androstenedione induced proliferation in MCF-7/Aro cells, suggesting that mTOR signaling is required for estrogen proliferative response in MCF-7 cells. Furthermore, combination therapy with letrozole and RAD001 resulted in increased inhibition of cell proliferation as well as a synergistic effect, even at suboptimal levels of RAD001. No evidence of antagonism was observed [36].

\section{Human pharmacokinetics}

The pharmacokinetic properties of rapamycin have been studied in healthy individuals, pediatric dialysis patients, hepatically impaired adult patients, and adult renal transplant patients. Oral doses of both liquid and pill forms of rapamycin are rapidly but variably absorbed. Mean time to peak concentrations range from 1 hour in healthy individuals to 2 hours in renal transplant patients. Half-life is upwards of 2.5 days. Metabolism is by the intestinal and hepatic CYP3A4 enzyme family, and $91 \%$ of the elimination of the drug is via the gastrointestinal tract. The area under the curve correlates well with peak and trough concentrations.

Patients who ingested the drug after a high fat breakfast did have a delayed time to maximum concentration (Cmax), and it is recommended that rapamycin be consistently taken with or without food. In a phase I pharmacokinetic study conducted in renal transplant patients, doses ranging from 0.5 to $6.5 \mathrm{mg} / \mathrm{m}^{2}$ were administered every 12 hours. Phase III studies to date have had concomitant use of cyclosporine or steroid, or both. At a dose of $2 \mathrm{mg} /$ day the rapamycin trough concentration was $8.58 \pm 4 \mathrm{ng} / \mathrm{ml}$ and at $5 \mathrm{mg} /$ day the trough was $17.3 \pm 7.4 \mathrm{ng} / \mathrm{ml}$. Rapamycin concentrations in stable renal transplant patients are dose proportional between 3 and $12 \mathrm{mg} / \mathrm{m}^{2}$. Also, in this population a loading dose of three times the maintenance dose provided a near steady state concentration within 1 day in most patients. Stable renal transplant recipients have received single doses of up to $21 \mathrm{mg} / \mathrm{m}^{2}$. No toxicity has been observed in any of several single dosing studies with

\section{Development of mammalian target of rapamycin inhibitors for cancer treatment}

Based on preclinical studies suggesting that inhibition of mTOR has antiproliferative effects in a variety of cancer models, clinical studies were initiated with two rapamycin analogs, namely RAD001 and CCl-779. Preliminary results from these studies indicate that these drugs are well tolerated and have promising anticancer activity [37]. The principal toxicities of $\mathrm{CCl}-779$ - the agent for which more clinical data are available - include thrombocytopenia, hyperlipidemia, skin toxicity, and elevation in liver function tests. These side effects were in general mild to moderate in intensity and not necessarily associated with administered dose of the drug. In addition, antitumor activity was demonstrated in a variety of tumor types, including breast cancer and renal cancer. A randomized phase II study of multiple dose levels of $\mathrm{CCl}-779$ in patients with advanced refractory renal cell carcinoma has shown antitumor activity and encouraging survival as well as drug tolerability [38].

Additionally, a multicenter European phase II study was conducted in 109 patients with advanced breast cancer [39]. Patients who had progressed on taxanes and anthracyclins were allowed to receive a weekly intravenous dose of CCl-779 at either $75 \mathrm{mg}$ or $225 \mathrm{mg}$. Clinical benefit was observed in 37\% of patients, including 10 partial responses and 26 patients with stable disease for longer than 8 weeks. Activity was seen at both dose levels, with a low toxicity profile. It is interesting to note that activity was even seen in patients with liver metastases at both dose levels but no response was seen in any of the 33 HER-2 negative patients. Further studies were initiated because of these promising results. Because of the association of hormone resistance and activation of the PI3K and mTOR pathways, development of clinical trials combining mTOR inhibitors and hormonal agents are logical. A randomized phase III, placebocontrolled, double-blind study of oral $\mathrm{CCl}-779$ administered in combination with letrozole versus letrozole alone in patients with estrogen-dependent breast cancer is ongoing. Combinations of mTOR inhibitors and cytotoxic agents are also expected.

\section{Conclusion}

The PI3K/Akt signaling pathway regulates many normal cellular processes including cellular proliferation, survival, growth and motility, all of which are critical processes for tumorigenesis. It is clear that alteration of this pathway occurs in many cancerous states, and perhaps targeted manipulation to optimize control of this pathway will mitigate its contribution to oncogenic activity. In several cancers, mTOR inhibitors have been shown to be promising agents in reducing tumor growth in vitro and in vivo, including renal cancer and breast cancer. Hopefully, with better understanding of these pathways and improved 
This article is the second in a review series on

New targets for therapy in breast cancer, edited by Stephen RD Johnston.

Other articles in the series can be found at http://breast-cancer-research.com/articles/ review-series.asp?series=bcr_NewTargets

'profiling' of individual patients tumors, future clinical trials and treatment options will identify and target those patients who will benefit from these directed therapies.

\section{Competing interests}

$\mathrm{HC}$ declares that she has no competing interests. $\mathrm{MH}$ has received reimbursements, fees, and funding from Genentec, Astra-Zeneca, OSI pharmaceuticals, Weth, and Brystol Myers Squibb.

\section{Acknowledgements}

Dr Hetty Carraway would like to acknowledge The Stetler Fund for the support for her research at the Sidney Kimmel Comprehensive Cancer Center at Johns Hopkins Hospital.

\section{References}

1. Tee AR, Manning BD, Roux PP, Cantley LC, Blenis J: Tuberous sclerosis complex gene products, Tuberin and Hararin, control mTOR signaling by acting as a GTPase-activating protein complex toward Rheb. Curr Bio/ 2003, 13:1259-1268.

2. Manning BD, Cantley LC: Rheb fills a GAP between TSC and TOR. Trends Biochem Sci 2003, 28:573-576.

3. Dancey J, Sausville EA: Issues and progress with protein kinase inhibitors for cancer treatment. Nat Rev Drug Discov 2003, 2:296-313.

4. Aronica SM, Katzellenbogen BS: Progesterone receptor regulation in uterine cells: stimulation by estrogen, cyclic adenosine $3^{\prime}, 5^{\prime}$-monophosphate, and insulin like growth factor $I$ and suppression by antiestrogens and protein kinase inhibitors. Endocrinology 1991, 128:2045-2052.

5. Pietras RJ, Arboleda J, Reese DM, Wongvipat N, Pegram MD, Ramos L, Gorman CM, Parker MG, Sliwkowski MX, Slamon DJ: Her-2 tyrosine kinase pathway targets estrogen receptor and promotes hormone independent growth in human breast cancer cells. Oncogene 1995, 10:2435-2446.

6. Smith CL: Crosstalk between peptide growth factor and estrogen receptor signaling pathways. Bio Reprod 1998, 58:627632.

7. Campbell RA, Bhat-Nakshatri P, Patel NM, Constantinidou D, Ali $\mathrm{S}$, Nakshatri H: Phosphatidylinositol-3-kinase/Akt mediated activation of estrogen alpha: a new model for anti-estrogen resistance. J Biol Chem 2001, 276:9817-9824.

8. Knuefermann C, Lu Y, Liu B, Jin W, Liang K, Wu L, Schmidt M, Mills GB, Mendelsohn J, Fan Z: HER2/PI-3K/Akt activation leads to a multidrug resistance in human breast adenocarcinoma cells. Oncogene 2003, 22:3205-3212.

9. Gibbons JJ, Discafani C, Peterson R, Hernandez R, Skotnicki J, Fruman D: The effect of $\mathrm{CCl}-779$, a novel macrolide anti-tumor agent, on the growth of human tumor cells in vitro and in nude mouse xenograft in vivo [abstract 2000]. Proc Am Assoc Cancer Res 1999, 40:301.

10. Guba M, von Breitenbuch P, Steinbauer M, Koehl G, Flegel S, Hornung M, Bruns CJ, Zuelke C, Farkas S, Anthuber M, et al.: Rapamycin inhibits primary and metastatic tumor growth by antiangiogenesis: involvement of vascular endothelial growth factor. Nat Med 2002, 8:10031-10033.

11. Eng CP, Seghgal SN, Vezina C: Activity of rapamycin (AY-22, 989) against transplanted tumors. J Antibio (Tokyo) 1984, 37: 1231-1237.
12. Dilling $M B$, Dias $P$, Shapiro $D N$ : Rapamycin selectively inhibits growth of childhood rhabdomyosarcoma cells through inhibition of signaling via the type I insulin growth receptor. Cancer Res 1994, 54:903-907.

13. Suefferlein, T., Rzengurt E: Rapamycin inhibits constitutive p70 $56 \mathrm{~K}$ phosphorylation, cell proliferation, and colony formation in small cell lung cancer cells. Cancer Res 1996, 56:3895-3897.

14. Fry MJ: Phosphoinositide 3-kinase signaling in breast cancer: how big a role might it play? Breast Cancer Res 2001, 3:304312.

15. Hu Q, Klippel A, Muslin AJ, Fantl WJ, Williams LT: Ras dependent induction of cellular responses by constitutively active phosphatidylinositol-3 kinase. Science 1995, 268:100-102.

16. Lee AV, Yee D: Insulin like growth factors and breast cancer. Biomed Pharmacother 1995, 49:415-421.

17. Scheid MP, Woodgett JR: Phosphatidylinositol-3 kinase signaling in mammary tumorigenesis. J Mammary Gland Biol Neoplasia 2001, 6:83-99.

18. Hankinson SE, Willett WC, Colditz GA, Hunter DJ, Michaud DS, Deroo B, Rosner B, Speizer FE, Pollak M: Circulating concentrations of insulin like growth factor-I and risk of breast cancer. Lancet 1998, 351:1393-1396.

19. Smith GD, Gunnell D, Holly J: Cancer and insulin like growth factor-I. A potential mechanism linking the environment with cancer risk. BMJ 2000, 321:847-848.

20. Pollack M: Insulin like growth factor physiology and cancer risk. Eur J Cancer 2000, 36:1224-1228.

21. $\mathrm{Yu} \mathrm{H}$, Rohan $\mathrm{T}$ : Role of the insulin like growth factor family in cancer development and progression. J Natl Cancer Inst 2000, 92:1472-1489.

22. Lee AV, Hilsenbeck SG, Yee D: IGF system components as prognostic markers in breast cancer. Breast Cancer Res Treat 1998, 47:295-302.

23. Samuels Y, Wang Z, Bardelli A, Silliman N, Ptak J, Szabo S, Yan $\mathrm{H}$, Gazdar A, Powell SM, Riggins GJ, et al:: High frequency of mutations of the PIK3CA gene in human cancers. Science 2004, 304:554.

24. Simoncini T, Hafezi-Moghadam A, Brazil DP, Ley K, Chin WW, Liao JK: Interaction of estrogen receptor with the regulatory subunit of phosphatidyl-inositol-3-OH-kinase. Nature 2000, 407:538-541.

25. deGraffenried L, Friedrichs W, Fulcher L, Silva J, Roth R, Hidalgo $\mathrm{M}$ : The $\mathrm{mTOR}$ inhibitor, $\mathrm{CCl}-779$, restores tamoxifen response in breast cancer cells with high Akt activity. Roc $14^{\text {th }} \mathrm{NCl}-$ EORTC-AACR symposium on molecular targets and cancer therapeutics [abstract \#528]. Eur J Cancer 2002, S158.

26. Cui X, Zhang P, Deng W, Oesterreich S, Lu Y, Mills GB, Lee AV: IGF-I inhibits progesterone expression in breast cancer via the PI3K/AKT/mTOR pathway: progesterone receptor as a potential indicator of growth factor activity in breast cancer. Mol Endocrinol 2003, 17:575-588.

27. Buckley MF, Sweeney KJ, Hamilton JA, Sini RL, Manning DL, Nicholson RI, deFazio A, Watts CK, Musgrove EA, Sutherland RL: Expression and amplification of cyclin genes in breast cancer. Oncogene 1993, 8:2127-2133.

28. Weinstat-Saslow D, Merino MJ, Manrow RE, Lawrence JA, Bluth RF, Wittenbel KD, Simpson JF, Page DL, Steeg PS: Overexpression of cyclin D mRNA distinguishes invasive and in situ breast carcinomas from non-malilgnant lesions. Nat Med 1995, 1:1257-1259.

29. Yakes FM, Chinratanalab W, Ritter CA, King W, Seelig S, Arteaga CL: Herceptin-induced inhibition of phosphatidylinositol-3 kinase and Akt is required for antibody-mediated effects on p27, cyclin D1, and antitumor action. Cancer Res 2002, 62: $4132-4141$.

30. Rhei E, Kang L, Bogomolniy F, Federici MG, Borgen PI, Boyd J: Mutation analysis of the putative tumor suppressor gene PTEN/MMAC1 in primary breast carcinomas. Cancer Res 1997, 57:3657-3659.

31. Mills GB, Lu Y, Fang X, Wang H, Eder A, Mao M, Swaby R, Cheng KW, Stokoe D, Siminovitch K, et al:: The role of genetic abnormalities of PTEN and the phosphatidylinosiyl 3 kinase pathway in breast and ovarian tumorigenesis, prognosis, and therapy. Semin Oncol 2001, Suppl 16:125-141.

32. Perren A, Weng LP, Boag AH, Ziebold U, Thakore K, Dahia PL, Komminoth P, Lees JA, Mulligan LM, Mutter GL, et al:: Immunohistochemical evidence of loss of PTEN expression in primary 
ductal adenocarcinomas of the breast. Am J Pathol 1999, 155: 1253-1260.

33. Stål O, Pérez-Tenorio G, Akerberg L, Olsson B, Nordenskjöld B, Skoog L, Rutqvist LE: AKT kinases in breast cancer and results of adjuvant therapy. Breast Cancer Res 2002, 5:R37-R44.

34. Neshat MS, Mellinghoff IK, Tran C, Stiles B, Thomas G, Petersen R, Frost P, Gibbons JJ, Wu H, Sawyers CL: Enhanced sensitivity of PTEN- deficient tumors to inhibition of FRAP/mTOR. Proc Natl Acad Sci USA 2001, 98:10314-10319.

35. Grünwald V, DeGraffenried L, Russel D, Friedrichs WE, Ray RB, Hidalgo M: Inhibitors of $\mathrm{mTOR}$ reverse doxorubicin resistance conferred by PTEN status in prostate cancer cells. Cancer Res 2002, 62:6141-6145.

36. Rudloff J, Boulay A, Zumstein-Mecker S, Evans DB, O'Reilly T, Lane $\mathrm{H}$ : The mTOR pathway in estrogen response: a potential for combining the rapamycin derivative RAD001 with the aromatase inhibitor letrozole in breast carcinomas [abstract]. Proc Am Assoc Cancer Res 2004, 45:A5619.

37. Raymond E, Alexandre J, Faivre S, Vera K, Materman E, Boni J, Leister C, Korth-Bradley J, Hanauske A, Armand JP: Safety and pharmacokinetics of escalated doses of weekly intravenous infusion of $\mathrm{CCl}-779$, a novel mTOR inhibitor, in patients with cancer. J Clin Oncol 2004, 22:2336-2347.

38. Atkins MB, Hidalgo M, Stadler WM, Logan TF, Dutcher JP, Hudes GR, Park Y, Liou SH, Marshall B, Boni JP, et al: Randomized phase II study of multiple dose levels of $\mathrm{CCl}-779$, a novel mammalian target of rapamycin kinase inhibitor, in patients with advanced refractory renal cell carcinoma. J Clin Oncol 2004, 22:909-918.

39. Chan S, Scheulen ME, Johnston S, Mross K, Piccart M, Hess D, Bouxin N, Azli N: Final results of a phase 2 study of single agent $\mathrm{CCl}-779$ in locally advanced or metastatic breast cancer failing prior anthracyclin and/or taxane regimens [abstract 346]. Breast Cancer Res Treat 2003, 82:s82. 